\title{
COMMUNICATION DIFFICULTIES AND PSYCHOLOGICAL STRESS IN PATIENTS RECEIVING MECHANICAL VENTILATION
}

\author{
Thapa $D^{1^{*}}$, Dahal $A^{2}$, Singh $R^{3}$
}

\begin{abstract}
Affiliation
1. Lecturer, Department of Nursing, Nobel medical College Teaching Hospital, Biratnagar, Nepal

2. Department of Nursing, Nobel medical College Teaching Hospital, Biratnagar, Nepal
\end{abstract}

\section{ARTICLE INFO}

Received : 10 January, 2019
Accepted : 07 August, 2019
Published : 31 August, 2019

(c) Authors retain copyright and grant the journal right of first publication with the work simultaneously licensed under Creative Commons Attribution License CC - BY 4.0 that allows others to share the work with an acknowledgment of the work's authorship and initial publication in this journal.

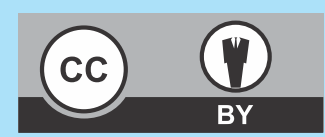

ORA 120

DOI: http://dx.doi.org/10.3126/bjhs.v4i2.25452

\section{* Corresponding Author} Ms. DejinaThapa

Lecturer (Nursing Department)

Nobel Medical College Teaching Hospital, Biratnagar, Nepal Email ID: dejinathapa21@gmail.com

ORCID ID: https://orcid.org/0000-0001-5764-1579

\section{Citation}

Thapa D, Dahal A, Singh R. Communication Difficulties and Psychological Stress in Patients Receiving Mechanical Ventilation. BJHS 2019;4(2)9: 718 - 723.

\section{ABSTRACT}

\section{Introduction}

Communication is fundamental for an individual to verbalize their feelings. Inability of the patient receiving mechanical ventilation to communicate the needs to the health care provider often leads to psychological stress.

\section{Objective}

The objective of the study is to assess the communication difficulties and psychological stress in patients receiving mechanical ventilation.

\section{Methodology}

A cross-sectional research design was used for the study. A total of 48 patient extubated within the preceding 72 hours, was taken as a sample by using a convenience sampling method. Data were collected by using a interview technique in patients from January-September 2018 from a 41bedded ICU at Nobel Medical College Teaching Hospital. Data analysis was done by descriptive and inferential statistics.

\section{Results}

Difficulty in communication was found where majority of the respondents $(82.29 \%)$ rated general communication as extremely hard. The study further revealed that $100 \%$ of the respondents used hands for pointing and gesturing followed by shaking heads $(65.38 \%)$, whisper $(19.23 \%)$ and writing (11.53\%). Sleeping and communication difficulty was the major problem $97.91 \%$ and $96.94 \%$ respectively. Majority of respondents(66.66\%)scored Intensive Care Psychological Assessment Tool more than 7. In addition, there is significant association between the sex, total length of ventilation and prior experience with ICU $(p=<0.05)$.

\section{Conclusion}

Patient with mechanical ventilation experience a moderate to extreme level of psychological stress because they have difficulty in communicating their needs. Alternative communication methods should be developed, and health care provider should be aware about the communication difficulties, thereby reducing the stress caused by ineffective communication.

\section{KEY WORD}

Communication difficulties; mechanical ventilation; psychological stress 


\section{INTRODUCTION}

Mechanical ventilation (MV) is an important device for respiratory failure patients. Mechanical ventilation greatly affects the production of voice, leaving patients unable to communicate their needs with nurses and the family. Over $50 \%$ of patients report communication challenges during mechanical ventilation as moderately to extremely stressful. ${ }^{1,2}$

Health personnel are aware of the importance of communication however such communication does not occur. ${ }^{3}$ Greater than 2.7 million patients in intensive care units (ICUs) in the United States each year are unable to communicate because of the presence of artificial airways and assisted ventilation. ${ }^{4}$ Several studies have found that there are a numerous barriers for communication like patients inability to write, difficulty in lip reading, nurses heavy work load, lack of training on communication. ${ }^{5}$ To minimize the communication barriers; assistive devices like picture, charts, alphabet board may be useful. ${ }^{6}$ Moreover advanced technological devices like computerized electronic voice output can also be used .

The communication problem during mechanical ventilation and distress of patient's inability to speak are vital to nurses and other health care providers, though only very less is known about the impact of the inability to speak on psychological distress. ${ }^{8,9}$ Inability to communicate causes great stress to patient who are treated with mechanical ventilation which lead to various psychological stress like anxiety, depression, anger and fear, panic, sleep disorders as well as decreased self esteem. , $^{8,10,11,12}$

Inability to communicate is a major source of stress for patients. In context of Nepal such type of study has not been done regarding the communication difficulties and psychological stress in patient receiving mechanical ventilation. Thus, in this study, communication difficulties, the number of communication methods used, perceived psychological stress, and selected baseline demographic variables associated with psychological stress among ICU patients treated with mechanical ventilation has been studied.

\section{METHODOLOGY}

A hospital based cross sectional study was conducted after approval by the institutional review Committee. A total of 48 patients were taken as a sample by using a convenience sampling method. Data were collected from medical charts and by using a interview technique in patients from January to September 2018 from a 41-bedded ICU at Nobel Medical College Teaching Hospital Sample size was calculated using the formula $n=1.96^{2} \times p \times(1-p) / 0.15^{2}$ with margin of error $20 \%$, study published from Portugal making a total of $48 .{ }^{13} \mathrm{~A}$ total of 1450 patients were admitted during the course of the study. After obtaining informed consent from the patient and who met the following inclusive criteria were selected as a sample: fully oriented to time, place and person, age 20 years or above; and extubation within 72 hours. Patients with psychiatric disorder and those who underwent tracheostomy were excluded from the study.
By using prefixed Pro-forma all the data were recorded which included demographic characteristics such as age/gender, educational level, occupation, length of ICU stay, diagnosis at the time of admission, days of intubation, prior history of ICU stay.

\section{MEASURES}

Communication difficulties was measured by using the ease of Communication Scale developed by Menzel. ${ }^{14}$ Alikert scale of 5 point was used from 0 ( not hard at all), 1 ( A little hard), 2 ( some what hard), 3 ( Quiet hard) to 4 (extremely hard) in which patients rated their perceived communication difficulty in general with visitor, doctor, nurses, and about the care provided. Higher the score greater the difficulties in communication.

Menzel communication checklist was used to evaluate the number of communication method ${ }^{14}$ which consists of 5 communication methods commonly used in the critical unit of the study area: gesturing, spelling words on a board, writing, whisper, picture board and shaking heads. Patient were asked to select the methods used in ICU.

Psychological stress related to ICU was measured by using Intensive care psychological assessment tool (IPAT) developed by Dorothy. ${ }^{15}$ The tool is valid and reliable. ${ }^{15}$ The tool was translated in Nepali and content validity of the tool was established by consulting with experts of concerned area and by the review of the related literatures. Pretesting was done among 8 respondents in which reliability of Nepali version was calculated. Cronbach's alpha coefficient was computed which was 0.79 which showed a good degree of internal consistency. Patient were asked to respond the 10 questionnaires: hopeless, tensed, Panicky, deliberate to harm, upset memories, sad, insomnia, communication difficulty, hallucinations as well as disorientation. Each score consists from 0 to 2 .A score $\geq 7$ indicates patient at risk.

The collected data was calculated by using Statistical Software Package for Social Sciences (SPSS 22 version).

\section{RESULTS}

\section{Socio Demographic characteristics of the respondents}

Of the study population 48, majority of the respondents were in the age group between $30-50$ years of age among them male were 29 (60.41\%)and female 19 (39.58\%). Similarly, majority of respondents were married 42 (87.5\%) and were literate. More than half of the respondents were living in urban area 28 (58.33\%) and occupation is agriculture 19 (39.58\%). Regarding the clinical diagnosis of the respondents, the most prevalent reasons for intubation was respiratory insufficiency $21(43.75 \%)$, followed by gastrointestinal $8(16.66 \%)$ whereas least was poisoning $3(6.25 \%)$. Majority of the respondents stayed in ICU for more than 7 days 26(54.16\%) and 24(50\%) ventilated for at least 72 hours whereas $37(77.08 \%)$ of respondents had no any history of admission in ICU . (Socio demographic table is presented in Table 1) 
Table 1: Socio demographic characteristics of the Respondents

\begin{tabular}{|c|c|c|}
\hline Demographic Characteristics & $\begin{array}{l}\text { Frequency } \\
\qquad(n=48)\end{array}$ & $\begin{array}{c}\text { Percentage } \\
\text { (\%) }\end{array}$ \\
\hline \multicolumn{3}{|l|}{ Age (in years) } \\
\hline Below 30 & 9 & 18.75 \\
\hline $30-50$ & 28 & 58.33 \\
\hline Above 50 & 11 & 22.91 \\
\hline \multicolumn{3}{|l|}{ Sex } \\
\hline Male & 29 & 60.41 \\
\hline Female & 19 & 39.58 \\
\hline \multicolumn{3}{|l|}{ Marital status } \\
\hline Married & 42 & 87.5 \\
\hline Unmarried & 6 & 12.5 \\
\hline \multicolumn{3}{|l|}{ Educational level } \\
\hline Illiterate & 9 & 18.75 \\
\hline Primary level & 12 & 25 \\
\hline $\begin{array}{l}\text { Secondary level } \\
\text { Higher secondary level and above }\end{array}$ & 18 & 37.5 \\
\hline Residence & 9 & 18.75 \\
\hline Urban & 28 & 58.33 \\
\hline Rural & 20 & 41.66 \\
\hline \multicolumn{3}{|l|}{ Occupation } \\
\hline Agriculture & 19 & 39.58 \\
\hline Business & 7 & 14.58 \\
\hline Services & 6 & 12.5 \\
\hline Housewife & 13 & 27.08 \\
\hline $\begin{array}{l}\text { Others } \\
\text { (carpenter, plumber, } \\
\text { manuallabourer,tea vendor etc) }\end{array}$ & 3 & 6.25 \\
\hline \multicolumn{3}{|l|}{ Diagnostic Category } \\
\hline Respiratory Insufficiency & 21 & 43.75 \\
\hline Gastrointestinal & 8 & 16.66 \\
\hline Cardiovascular & 6 & 12.5 \\
\hline Renal & 4 & 8.33 \\
\hline Neuro & 2 & 4.16 \\
\hline Metabolic & 4 & 8.33 \\
\hline Poison & 3 & 6.25 \\
\hline \multicolumn{3}{|l|}{ Length of ICU stay } \\
\hline Less than 7 days & 22 & 45.83 \\
\hline More than 7 days & 26 & 54.16 \\
\hline \multicolumn{3}{|l|}{ Total length of ventilation } \\
\hline At least 24 hours & 9 & 18.75 \\
\hline $24-48$ hours & 15 & 31.25 \\
\hline 72 hours & 24 & 50 \\
\hline \multicolumn{3}{|l|}{ Prior experience with ICU } \\
\hline Yes & 11 & 22.91 \\
\hline No & 37 & 77.08 \\
\hline
\end{tabular}

\section{Ease of Communication}

The histogram in figure 1 shows the distribution of the respondents answer to ease of communication scale. The majority of the respondents $39(81.25 \%)$ rated general communication to be 'extremely hard', 5(10.41\%) rated communication to be 'quiet hard', $3(6.25 \%)$ responded for 'somewhat' difficulty and only $1(2.08 \%)$ of the respondents rated communication difficulty be 'little bit'.

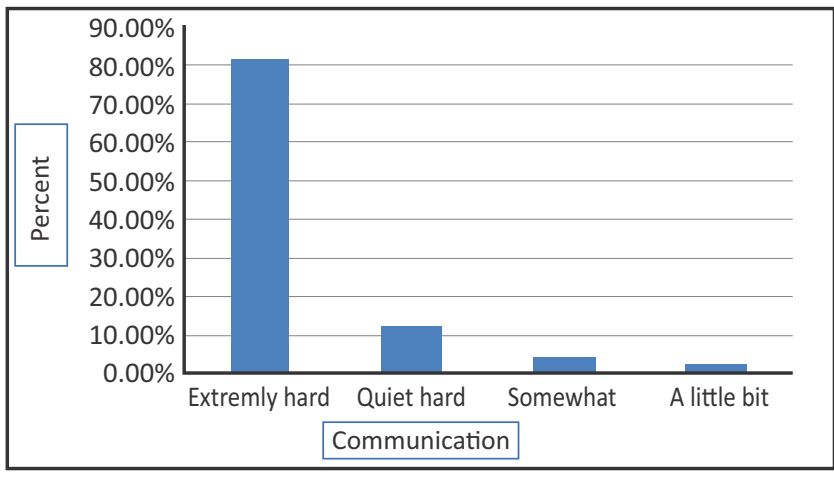

Figure 1: Patients ratings of Ease of Communication scale

\section{Patient Communication Methods}

Pointing was the most common communication technique used $48(100 \%)$, followed by shaking heads $32(66.66 \%)$, moving lips $10(20.83 \%)$ whereas writing was the least common method 6(12.5\%) [shown in figure 2].

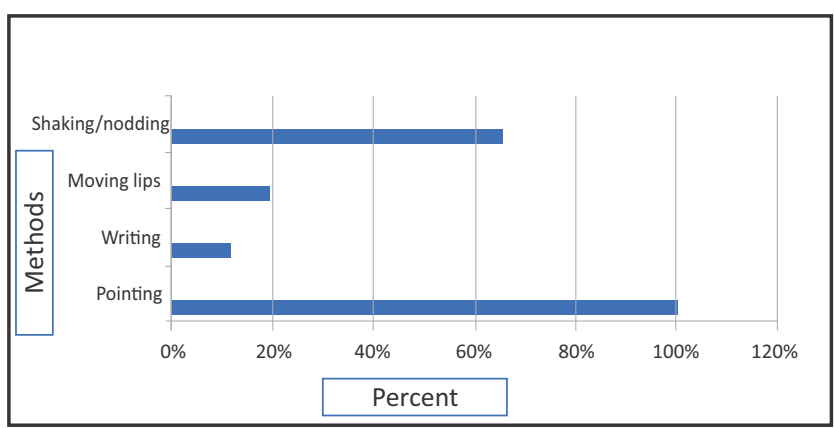

Figure 2 : Communication methods used by the patients

\section{Frequency of Psychological stress of respondents}

Table 2 depicts that, almost all the respondents have difficulty in sleep 47(97.91\%) and communication 46(96.94) respectively. However, very few of the respondents have a problem like hallucinations 5 (10.41) and disorientations $3(6.24 \%)$ respectively. (Table 2 presents the psychological stress during mechanical ventilation).

Table 2 Descriptions of Intensive care psychological assessment tool (IPAT) frequencies of respondents.

\begin{tabular}{|c|c|c|c|c|c|}
\hline \multirow[t]{2}{*}{ S. $\mathrm{N}$} & \multirow[t]{2}{*}{ IPAT questions } & \multicolumn{3}{|c|}{ Response (n /\%) } & \multirow[t]{2}{*}{$\begin{array}{l}\mathrm{n}=48 \\
\text { Mean } \pm \mathrm{SD}\end{array}$} \\
\hline & & No & Yes, a Bit & Yes, a Lot & \\
\hline 1. & Hopeless & $12(25)$ & $34(70.83)$ & $2(4.16)$ & $3.83 \pm 0.38$ \\
\hline 2. & Tense & $3(6.25)$ & 35 (72.91) & $10((20.83)$ & $3.80 \pm 0.44$ \\
\hline 3. & Panicky & $43(89.58)$ & $5(10.41)$ & - & $3.76 \pm 0.34$ \\
\hline 4. & $\begin{array}{l}\text { Deliberately trying to } \\
\text { harm }\end{array}$ & $44(91.66)$ & $4(8.33)$ & - & $4.03 \pm 0.30$ \\
\hline 5. & Upsetting memories & $42(87.5)$ & $6(12.5)$ & - & $4.54 \pm 0.66$ \\
\hline 6. & Sad & $5(10.41)$ & $39(81.25)$ & $4(8.33)$ & $3.72 \pm 0.51$ \\
\hline 7. & Difficult to sleep & - & $47(97.91)$ & $1(2.08)$ & $4.21 \pm 0.83$ \\
\hline 8. & Difficult to communicate & - & $46(96.94)$ & $2(4.16)$ & $4.03 \pm 0.58$ \\
\hline 9. & Hallucinations & $43(89.58)$ & $5(10.41)$ & - & $4.71 \pm 0.75$ \\
\hline 10. & Disorientated & $45(93.75)$ & $3(6.25)$ & - & $4.69 \pm 0.73$ \\
\hline
\end{tabular}

IPAT total score

Table 3: Respondent's overall Score of Intensive care psychological assessment tool (IPAT) $\quad \mathrm{n}=48$

IPAT Score Frequency (n) Percentage (\%)

$\begin{array}{lll}\geq 7 \text { Patient at risk } & 32 & 66.66 \\ \leq 7 \text { Patient not in risk } & 16 & 33.33\end{array}$


$66.66 \%$ of the respondents score more than 7 i.e. they are at risk whereas $33.33 \%$ of the respondents score below 7 . From this table it is concluded that, patient should provide the psychological support as required.

\section{Association between IPAT score with selected Demographic Variables}

Table 4 reveals association between psychological stress with demographic variables. To associate the level of psychological stress with demographic variables the Chisquare test has been used. There is significant association between the sex, total length of ventilation and prior experience with ICU $(p=<0.05)$ and others demographic variables did not show any significant association with the IPAT score.

\begin{tabular}{|c|c|c|c|c|c|}
\hline \multirow{2}{*}{\multicolumn{4}{|c|}{$\begin{array}{l}\text { Table 4: Association bet } \\
\text { Demographic variables }\end{array}$}} & \multicolumn{2}{|c|}{$\begin{array}{l}\text { e with selected } \\
\qquad n=48\end{array}$} \\
\hline & & & & \multirow[b]{2}{*}{$\begin{array}{l}\text { square } \\
\text { test value }\end{array}$} & \multirow[b]{2}{*}{ P Value } \\
\hline  & $n$ (48) & $\begin{array}{l}\text { At risk } \\
n(\%)\end{array}$ & $\begin{array}{c}\text { Not in risk } \\
n(\%)\end{array}$ & & \\
\hline Age (in years) & & & & - & FET value: \\
\hline Below 30 & 9 & $6(66.66)$ & $3(33.33)$ & & $>0.05 \mathrm{NS}$ \\
\hline $30-50$ & 28 & $17(60.71)$ & $11(39.28)$ & & \\
\hline Above 50 & 11 & $6(54.54)$ & $5(45.45)$ & & \\
\hline \multicolumn{6}{|l|}{ Sex } \\
\hline Male & 29 & $23(79.31)$ & $7(20.66)$ & 5.783 & $<0.05 \mathrm{~S}^{*}$ \\
\hline Female & 19 & $12(63.15)$ & $7(36.84)$ & 0.100 & \\
\hline \multicolumn{6}{|l|}{ Educational level } \\
\hline Illiterate & 9 & $5(55.55)$ & $4(44.44)$ & - & FET value: \\
\hline Primary level & 12 & $8(66.66)$ & $4(33.33)$ & & $>0.05 \mathrm{NS}$ \\
\hline Secondary level & 18 & $11(61.11)$ & $7(38.88)$ & & \\
\hline Higher secondary & & & & & \\
\hline level and above & 9 & $5(55.55)$ & $4(44.44)$ & & \\
\hline \multicolumn{6}{|l|}{ Diagnostic Category } \\
\hline Respiratory Insufficiency & 21 & $15(71.42)$ & $7(28.57)$ & - & FET value: \\
\hline Gastrointestinal & 8 & $5(62.5)$ & $3(37.5)$ & & $>0.05 \mathrm{NS}$ \\
\hline Cardiovascular & 6 & $4(66.66)$ & $2(44.66)$ & & \\
\hline Renal & 4 & $3(75)$ & $1(25)$ & & \\
\hline $\begin{array}{l}\text { Other (Neuro, } \\
\text { metabolic and poison) }\end{array}$ & 9 & $6(66.66)$ & $3(44.44)$ & & \\
\hline \multicolumn{6}{|l|}{ Length of ICU stay } \\
\hline Less than 7 days & 22 & $14(63.63)$ & $8(36.36)$ & 1.414 & $>0.05 \mathrm{NS}$ \\
\hline More than 7 days & 26 & $15(57.61)$ & $11(42.30)$ & & \\
\hline \multicolumn{6}{|l|}{$\begin{array}{l}\text { Total length of } \\
\text { ventilation }\end{array}$} \\
\hline At least 24 hours & 9 & $7(63.63)$ & $2(18.88)$ & - & FET value: \\
\hline $24-48$ hours & 15 & $8(53.33)$ & $7(46.66)$ & & $<0.05 \mathrm{~S}^{*}$ \\
\hline 72 hours & 24 & $13(54.16)$ & $11(45.83)$ & & \\
\hline \multicolumn{6}{|l|}{ Prior experience with ICU } \\
\hline Yes & 11 & $7(63.63)$ & $4(36.36)$ & 5.036 & $<0.05 \mathrm{~S}^{*}$ \\
\hline No & 37 & $24(6486)$ & $13(3513)$ & & \\
\hline
\end{tabular}

Key: NS: Not significant, $\mathrm{S}^{*}$ : Significant

\section{DISCUSSION}

There are several studies regarding communication difficulties in ICU but only few studies carried out in relation with communication difficulties and psychological stress. Our research is one of the efforts to examine the response of intensive care unit patients. In our study we found that inability to speak during mechanical ventilation is a source for numerous negative feelings. This result is similar with the previous research of Rabia et al that indicated that patient treated with mechanical ventilation cannot speak and communicate their needs, so they experience the psychological stress.

Regarding the patient ratings of communication difficulty differ markedly, in our study patient rated communication difficulty was extremely hard (81.25\%). These results are not supported by findings of the study conducted by Happ $\mathrm{M} \mathrm{B}$ et al showing that only $40 \%$ rated communication as somewhat hard to extremely hard. The reasons for patient ratings may have been affected by in adequate care in addressing the basic needs and their frustration with their difficulty to speak. This finding concludes that there must be adequate nursing staff in ICU so that patient need can be carefully addressed.

Regarding communication methods, only few methods of communication like head nodding, pointing (100\%)were used, unfortunately no communication charts or assistive communication were observed in our study which is inconsistent with the findings of study done by O'Connell $\mathrm{E}$ and Landers $M$ where they used advanced methods of communication like electronic voice, alphabet board, word picture. ${ }^{17}$ Patient communication methods have not been changed since from a decade. Clearly, approaches to assistive communication materials is needed in the ICU which facilitate the effective communication between patient and the nurse.

Our study proved that patient admitted in Intensive care units frequently experienced stress due to mechanical ventilator; nearly $80 \%$ of the respondents feel fear, bored, sad, and communication difficulty. Comparable result were obtained in two of the study done by Sharma et al and 0 Connell et al. ${ }^{18,19}$ Although this results suggests that providing effective and appropriate communication methods may help to reduce the emotional stress. In additional, patient on mechanical ventilator experiences sleep deprivation. ${ }^{20}$ In our study we found the same and these findings is consistent with the study done by Hu RFet al. ${ }^{21}$ To improve the sleep quality several strategies can be adopted like dim light during night, minimizing the noise, and limiting the nursing basic care during night. ${ }^{22}$ In addition, cognitive abilities is also impaired in ICU where $10 \%$ of the patient experienced hallucinations along with disorientations in our study. Similarly, in another study found that $55 \%$ of the patient were confused in day and night as by Wade et al. ${ }^{23}$ The result suggests that psychological therapy can be introduced in critical ill patient.

During ICU stay patient are risk of developing psychological stress. In our study, $66.66 \%$ of the respondents score more than 7 IPAT score. However, no such similar studies were found in the literature using the IPAT. However, the findings suggest that IPAT can be used as a screening tool for detecting psychological stress. Furthermore, it should be used routinely in ICU to find out the acute distress and decrease the future psychological morbidity. ${ }^{14}$

The main responsibility of health care personnel is to provide comfort to the patient. In our study, we found that the sex, duration of ventilation and prior experience shows association $(<0.05)$ with psychological stress contradicting findings were from other studies Brumme, Saeed AM, and Wilcox et al. ${ }^{24-26}$ A possible explanation of the findings may 
be because of small sample size.

\section{CONCLUSION}

On the basic of study findings, it is concluded that Communication difficulties and psychological distress was the major problem faced by patient who are under mechanical ventilator. Patient rated communication difficulty as extremely hard $81.25 \%$. Patient cannot express their basis needs as a result they experience a multiple of negative thoughts. In addition, more than $60 \%$ of the patient are at risk of developing psychological stress. There is a association between the sex, total length of ventilation and prior experience with ICU $(<0.05)$. Therefore, effective communication and the basic needs of the patient should be addressed by health personnel working in the ICU to reduce the psychological stress.

\section{RECOMMENDATIONS}

In Nepal, there is currently no follow-up of patients once they have been discharged from an ICU. Limited evidence exists as the ICU team has only record of either death or discharge. A follow up for a patient can be introduced in the OPD. We also recommend intervention to reduce psychological stress: reinforcing the nurses by providing the basic nursing care for example; addressing the basic needs of patient, promoting comfortable positioning, providing periods of uninterrupted sleep, ensuring a privacy, reducing environmental noise and lighting, ensuring and providing effective communication could all assist in reducing the stress a patient has to contend with.

\section{LIMITATION OF THE STUDY}

Despite the fact our study also has few limitations; there is a lack of control group for comparison. As it is cross sectional research design, casual inferences between the communication difficulties and psychological distress could not be established. Our assessment of psychological distress was only based on presence and absence of symptoms.

\section{ACKNOWLEDGEMENT}

We thank all the ICU team for the support and cooperation.

\section{CONFLICT OF INTEREST}

Author declare no conflict of interest.

\section{FINANCIALDISCLOSURE}

No funding has received.

\section{REFERENCES}

1. Rotondi AJ, Chelluri L, Sirio C, Mendelsohn A, Schulz R, Belle S, Im K, Donahoe M, Pinsky MR. Patients' recollections of stressful experiences while receiving prolonged mechanical ventilation in an intensive care unit. Critical care medicine. 2002 Apr 1;30(4):74652.PMID:11940739

2. Dithole K, Sibanda S, Moleki MM, Thupayagale-Tshweneagae G. Exploring communication challenges between nurses and mechanically ventilated patients in the intensive care unit: a structured review. Worldviews on Evidence-Based Nursing. 2016 Jun 1;13(3):197-206. doi: 10.1111/wvn.12146.

3. Happ MB, Garrett K, Thomas DD, et al. Nurse-patient communication interactions in the intensive care unit. American Journal of Critical Care. 2011;20(2):e28-e40. doi: 10.4037/ajcc2011433

4. Guttormson JL, Bremer KL, Jones RM. "Not being able to talk was horrid": A descriptive, correlational study of communication during mechanical ventilation. Intensive and Critical Care Nursing. 2015; Jun 1;31(3):179-6.https://doi.org/10.1016/j.iccn.2014.10.007

5. Olding, M., McMillan, S. E., Reeves, S., Schmitt, M. H., Puntillo, K., \& Kitto, S. Patient and family involvement in adult critical and intensive care settings: a scoping review. Health expectations. 2016; 19(6), 1183-1202.doi: 10.1111/hex.12402

6. Finke $E H$, Light J, Kitko L. A systematic review of the effectiveness of nurse communication with patients with complex communication needs with a focus on the use of augmentative and alternative communication. Journal of clinical nursing. 2008; 17(16), 2102-2115.https://doi.org/ 10.1111/j.1365-2702.2008.02373.x

7. Happ MB. Communicating with mechanically ventilated patients: state of the science. American Association of critical care. 2001;12 (2) :247-258.PMID: 11759552

8. Khalaila R, Zbidat W, Anwar K, Bayya A, Linton DM, Sviri S. Communication difficulties and psychoemotional distress in patients receiving mechanical ventilation. American Journal of Critical Care. 2011 Nov 1;20(6):470-9. doi: 10.4037/ajcc2011989

9. Loghmani L, Borhani F, Abbaszadeh A. Factors affecting the nursepatients' family communication in intensive care unit of kerman: a qualitative study. Journal of caring sciences. 2014 Mar;3(1):67. doi: 10.5681/jcs.2014.008

10. Holm A, Dreyer P. Nurse patient communication within a context of non sedated mechanical ventilation: A hermeneutic-phenomenological study. Nursing Critical care Care. 2018 Mar;23(2) :88-94. DOI:10. 1111/nicc.12297

11. Carroll SM. Nonvocal ventilated patients perceptions of being understood. Western Journal of Nursing Research. 2004 Feb;26(1):85-103. https://doi.org/10.1177/0193945903259462

12. Samuelson KA, Lundberg D, Fridlund B. Stressful memories and psychological distress in adult mechanically ventilated intensive care patients-a 2-month follow-up study. ActaAnaesthesiologica Scandinavica. 2007 Jul;51(6):671-8.https://doi.org/10.1111/j.13996576.2007.01292.x

13. Martinho IF and Rodrigues M. Communication of mechanically ventilated patients in intensive care units. Rev. bras. ter. intensiva . 2016; 28 no. http://dx.doi.org/10.5935/0103-507X.20160027.

14. Menzel LK. Factors related to the emotional responses of intubated patients to being unable to speak. Heart Lung.1998;27:245-252. PMID: 9713716

15. Wade DM, Hankins M, Smyth DA, et al. Detecting acute distress and risk of future psychological morbidity in critically ill patients: validation of the intensive care psychological assessment tool. Crit Care. 2014;18(5):519. Doi:10.1186/s13054-014-0519-8 
16. Hoorn S.T, Elbers P. W, Girbes A.R and Tuinman P.R Communicating with conscious and mechanically ventilated critically ill patients: a systematic review. Critical Care.2016 20:333.https:// doi.org/ 10.1186/s13054-016-1483-2

17. Mohammad H. Mobasheri, Dominic King, Simon Judge, Faizan Arshad, and Marius Larsen et al.Communication aid requirements of intensive care unit patients with transient speech loss, Augmentative and Alternative Communication. 2016; 32:4, 261-271, DOI: 10.1080/07434618.2016.1235610

18. Sharma, G., Maben, E. V. S., Kotian, M. S., \&Ganaraja, B. Psychological evaluation of patients in critical care/intensive care unit and patients admitted in wards. Journal of clinical and diagnostic research.2016; 8(12), WC01. doi: 10.7860/JCDR/2014/10293.5297

19. O'Connell E, Landers M. The importance of critical care nurses' caring behaviours as perceived by nurses and relatives. Intensive and Critical Care Nursing. 2018; 24(6), 349-358. https://doi.org/ 10.1016/j.iccn.2008.04.002

20. Kamdar B B, Needhan M D and Coolop N .ASleep Deprivation in Critical Illness: Its Role in Physical and Psychological Recovery. Journal of Intensive Care Medicine. 2012 Mar; 27(2): 97-111.. doi: [10.1177/0885066610394322]

21. Friese RS, Diaz-Arrastia R, McBride D, Frankel H, Gentilello LM. Quantity and quality of sleep in the surgical intensive care unit: are our patients sleeping? Journal of Trauma and Acute Care Surgery. 2007; 63(6), 1210-1214. doi: 10.1097/TA.0b013e31815b83d7.
22. Hu RF, Jiang XY, Zeng YM, Chen XY, Zhang YH. Effects of earplugs and eye masks on nocturnal sleep, melatonin and cortisol in a simulated intensive care unit environment. Critical Care. 2010; 14(2), R66. doi: https://doi.org/10.1186/cc8965

23. Wade $D$, Als $N$, Bell $V$ on behalf of the POPPI investigators, et al. Providing psychological support to people in intensive care: development and feasibility study of a nurse-led intervention to prevent acute stress and long-term morbidity. BMJ Open. $2018 \mathrm{Jul}$ 23;8(7):e021083. doi: 10.1136/bmjopen-2017-021083./ PMID: 30037868

24. Brummel, N. E., \& Girard, T. D. Preventing delirium in the intensive care unit. Critical care clinics. 2013; 29(1), 51-65. doi: 10.1016/ j.ccc. 2012.10.007

25. Saeed AM, Galal I H, Shanta A K. Evaluation of the psychological status of patients during and after weaning from mechanical ventilation. Egyptian Journal of Bronchology. 2014; 8(2), 160. DOI: 10.4103/ 1687-8426.145718

26. Wilcox, M. E., Lim, A. S., Mc Andrews, M. P., Wennberg, R. A., Pinto, R. L., Black, S. E., \& Rubenfeld, G. D. A study protocol for an observational cohort investigating Cognitive outcomes and Wellness in survivors of critical illness: the COGWELL study. BMJ Open. 2017 Jul 13;7(7):e015600. doi: 10.1136/bmjopen-2016-015600. 